\title{
La profecía de Apolo en El rapto de Helena de Draconcio (Romul. 8) ${ }^{1}$
}

En un incisivo artículo sobre las Medeas de Draconcio y de Hosidio Geta, Marta Malamud coloca como epígrafe los dos últimos versos de la Medea de Séneca-per alta uade spatia sublime aetheris, / testare nullos esse, qua ueheris, deos ${ }^{2}-\mathrm{y}$ señala que, deleitados por la visión de la hechicera al elevarse sobre el carro tirado por serpientes, los espectadores olvidamos preguntarnos por la dirección de ese vuelo, emprendido desde la escena romana, que la llevaría a exiliarse con gran éxito en el norte de África ${ }^{3}$. Cuando el carro alado de Medea experimenta una reconfiguración estructural en el centón de Hosidio Geta, para deslizarse luego bajo la pluma de Draconcio, las citadas palabras finales de Jasón en la tragedia de Séneca adquieren -en el plano extradiegético- la misma capacidad de incomodar que aún conserva la profecía de Poseidón sobre Eneas en la Ilíada. De alguna manera, la Medea de Séneca emprende el vuelo hacia un sitio donde los dioses del panteón grecolatino ya no existen, pero no sólo en el plano filosófico del contexto enunciativo original, sino también en el nuevo horizonte religioso del norte de África. Ausentes en el cielo estoico, ausentes en el cielo cristiano, los dioses paganos podrían pensarse incluso privados del exilio literario emprendido por Medea. Sin embargo, la función estructural desempeñada por Apolo en El rapto de Helena nos permitirá observar cómo, tras el marco de la aparente hospitalidad ofrecida por el tema mitológico abordado, subyace en realidad el propósito

1 Este trabajo, desarrollado como Investigadora Asistente del CONICET, ha sido posible gracias a los subsidios para investigación otorgados por la ANPCyT (PICT $2013 \mathrm{~N}^{\circ}$ 405), por el CONICET (PIP 2014$2016 \mathrm{~N}^{\circ} 00089$ ), y por la SGCyT de la Universidad Nacional del Sur (PGI 24/I 227).

2 Sen. Med. 1026-1027: "Aléjate a través de los profundos espacios por el elevado éter y atestigua que no hay dioses allí hacia donde vas". Salvo en aquellos casos donde se indica otro autor, las traducciones de los textos latinos incluidos en este trabajo han sido realizadas por mí. Citamos todos textos pertenecientes a los autores latinos anteriores al siglo III d.C. por las ediciones incluidas en Latin Library Texts, PHI CD ROM 5.3, Los Altos, The Packard Humanities Institute, 1991.

3 Cf. Malamud, M. A., "Double, double: Two African Medeas", Ramus 41, 2014, 161-189.

Cita sugerida: Marrón, G. A. (2017). La profecía de Apolo en El rapto de Helena de Draconcio (Romul. 8). Auster, (22), e039. Recuperado de: http://doi.org/10.24215/23468890e39 
de cuestionar a las divinidades de la antigüedad grecolatina y de reinterpretar la trama narrativa del mito en términos cristianos ${ }^{4}$. Para ello, tomaremos como referencia la particular evocación del templo consagrado a Apolo en Timbra, y destinaremos el apartado inicial de este trabajo a demostrar la disputa de sentido entablada por Draconcio a partir de la apropiación y reinserción de ciertos sintagmas de Virgilio y de Estacio, orientados a establecer la naturaleza falaz y engañosa del discurso pronunciado por el dios de Timbra ante los troyanos en el poema. En la segunda parte, complementaremos dicho análisis y explicaremos por qué la caracterización despectiva de Apolo trasciende el universo textual de la obra de Draconcio y se proyecta hacia el de la Eneida, al proponer una lectura que subvierte el sentido original del poema virgiliano y se inscribe en la misma línea exegética desarrollada en África, un siglo antes, por Agustín de Hipona.

Como ha sido ya señalado por $\mathrm{Wasyl}^{5}$, en cada una de las cinco secciones o escenas principales de El rapto de Helena, se privilegian convenciones literarias características de distintos géneros, tales como la controversia, la épica, la pantomima y, puntualmente, en el marco del fragmento que nos ocupa, la tragedia. La escena comienza con el arribo de Paris a Troya -acompañado por una serie de presagios funestos- que interrumpe la realización de un sacrificio a Minerva. Tras presentarse como hijo de Príamo y Hécuba, el pastor exhibe algunos objetos junto a los que fue expuesto, establece su pertenencia al linaje real y recibe, de inmediato, el afecto sincero y culposo de sus progenitores. A continuación, interviene Heleno (Drac. Romul. VIII,

4 En tal sentido, seguimos la línea interpretativa propuesta por Simons, R., Dracontius und der Mythos: christliche Weltsicht und Pagane Kultur in der ausgehenden Spätantike, München, 2005, 289-290 y De Gaetano, M., Scuola e Potere in Draconzio, Alessandria, Edizioni dell'Orso, 2009, 171-172, quienes ubican la intervención de Apolo en El rapto de Helena dentro de la misma línea que los textos polémicos cristianos de Lactancio y de Agustín de Hipona. Para otras posiciones críticas sobre el tema, cf., por ejemplo, Wolff, É., "Les préfaces programmatiques de Dracontius", en: Galland-Hallyn, P. y Zarini, V., Manifestes littéraires dans la latinité tardive. Poétique et rhétorique, Paris, Institut d'Études Augustiniennes, 2009, 133-143; y Stoehr-Monjou, A., "L'apparition d'Apollon dans le Rapt d'Hélène de Dracontius: mise en scène d'une réécriture sous forme de mosaïque virgilienne (Romul. 8, 183-212)", en: Herbert de la Portbarré-Viard, G. y Stoehr-Monjou, A., Studium in libris. Mélanges en l'honneur de JeanLouis Charlet, Paris, Institut d'Ėtudes Augustiniennes, 2016, 139-156.

5 Cf. Wasyl, A. M., Genres rediscovered: Studies in Latin Miniature Epic, Love Elegy and Epigram of the Romano-Barbaric Age, Kraków, Jagiellonian University Press, 2011, 79-85. 
120-133), quien alude al sueño premonitorio del tizón encendido engendrado por Hécuba y enuncia la inevitable serie de acontecimientos futuros: el rapto de Helena, las mil naves griegas, la victoria de Aquiles, el cadáver de Héctor, la muerte de Troilo, el incendio de Troya, e incluso su propio enlace con Andrómaca, una vez muerto Pirro. Luego, el poeta inserta un segundo discurso -mucho más extenso- a cargo de Casandra (Drac. Romul. VIII, 135-182), quien profetiza el destino de Héctor, la violación que ella misma sufrirá por parte de Áyax en el templo, el derrumbe de la ciudad bajo las llamas, el cadáver insepulto de Príamo, la metamorfosis de Hécuba en perra, el cuerpo de Astianacte arrojado desde las murallas, la presencia de Bellona como madrina de la espartana, la muerte de Paris, la crueldad de Pirro y el carácter implacable de Aquiles. A diferencia de Heleno -que parece resignado a la imposibilidad de revertir el destino-, la sacerdotisa pide a los teucros matar a su hermano -culpable de sacrilegio, al haber participado como juez en la disputa divina- para salvaguardar el futuro de Troya ${ }^{6}$.

En el episodio descripto, se plantea un contraste dramático entre los parlamentos de ambos adivinos y el de Apolo (Drac. Romul. VIII, 188-212), cuya intervención -a modo de deus ex machina- resulta determinante para el recibimiento y la reinserción de Paris en la familia real ${ }^{7}$. El dios comienza su discurso desacreditando las palabras de sus dos sacerdotes, y sostiene que los hados prohíben apartar al pastor del palacio de Príamo. Anuncia que sólo Paris podrá derribar al magnánimo Aquiles, que los troyanos recibirán en posesión el mundo entero ${ }^{8}$, que su estirpe reinará durante muchos años y que les ha sido concedido un imperio sin fin. A su vez, afirma que ningún juez mortal puede dictar sentencia contra quien ha juzgado entre divinidades, sostiene que las Parcas lo necesitan, insta a los troyanos a vestirlo de púrpura, y alude a su propia

6 Para un análisis detallado de las diferencias de secuenciación cronológica en los hechos anunciados por ambas profecías, cf. Guerrieri, S., "Scene di profezia nel De raptu Helenae di Draconzio: riprese di moduli epici e tragici", Aitia, 6, 2016, §1-32, particularmente, §8-13.

7 Cf. Bretzigheimer, G., "Dracontius' Konzeption des Kleinepos De raptu Helenae (Romul. 8)", RhM, 153, 361-400, en particular 382; Wasyl, Genres rediscovered, 52; y Guerrieri, "Scene di profezia nel De raptu Helenae", §16. Este último autor intenta establecer, precisamente, las fuentes de la intervención de Apolo como deux ex machina en el poema de Draconcio, tomando como referencia -a partir de los fragmentos conservados- la posible función desempeñada por el dios en las tragedias Alexandros, de Eurípides y Alexander, de Enio. Sobre el tema, ver también Stoehr-Monjou, "L'apparition d'Apollon dans le Rapt d'Hélène", 140, n. 5 y n. 6, donde se sintetiza el estado de la cuestión acerca de la aparición de Apolo como deus ex machina en El rapto de Helena.

8 Con respecto a la extensión territorial del imperio y su vínculo con las profecías de la Eneida y con Drac. laud. III, 159-168, cf. Stoehr-Monjou, "L'apparition d'Apollon dans le Rapt d'Hélène”, 144-145. 
condición circunstancial de pastor - como sirviente de Admeto- para indicar que Paris no debe avergonzarse de haber apacentado ovejas en el Ida.

Antes de la intervención de Apolo, Draconcio incluye, tanto en el vaticinio de Heleno, como en el de Casandra, alusiones a un verso de la Tebaida de Estacio, que corresponde, en su contexto original, a las palabras finales pronunciadas por otro adivino, Anfiarao, al comprender la imposibilidad de persuadir a Capaneo para que no emprenda la expedición contra Tebas:

Sed quid uana cano, quid fixos arceo casus?

Ibimus. (Stat. Theb. III, 646-647)

¿Pero por qué canto inútiles revelaciones, por qué rechazo un derrumbe prefijado?

Iremos.

Sed quid fata ueto, quid fixos arceo casus?

cum nihil aduersis prosit prudentia ${ }^{9}$ signis? (Drac. Romul. VIII, 131-132) ${ }^{10}$

¿Pero por qué me opongo a los hados, por qué rechazo un derrumbe prefijado, cuando la predicción nada aporta ante signos adversos?

sed quid uana cano? (Drac. Romul. VIII, 152)

¿Pero por qué canto inútiles revelaciones?

Excepto por la inclusión del sintagma fata ueto, el verso de Estacio se repite casi completo en el discurso de Heleno. El parlamento de Casandra, en cambio, incluye sólo el hemistiquio inicial que, sin modificación alguna, se enlaza tanto con la omisión del sintagma uana cano en la profecía previa, como con su fuente original, el pasaje de la Tebaida. Draconcio atribuye el verbo cano a la intervención de la sacerdotisa en cuatro ocasiones $^{11}$, pero nunca a las palabras articuladas por Heleno, cuyo vaticinio parece pertenecer aquí a un orden diferente al de Anfiarao y al de Casandra, tal vez ligado con

9 Cf. las palabras de Heleno en Verg. Aen. III, 433-434: si qua est Heleno prudentia uati, / si qua fides. 10 Citamos las obras de Draconcio por las ediciones de Moussy, C. y Camus, C., Dracontius, Oeuvres, $t$. I y II, Paris, Les Belles Lettres, 2da ed., 2002 [1988]; Bouquet, J., Dracontius, Oeuvres, t. III, Paris, Les Belles Lettres, 2da ed., 2002 [1995]; y Wolff, É., Dracontius, Oeuvres, t. IV, Paris, Les Belles Lettres, 2da ed., 2002 [1996].

11 Cf. Drac. Romul. VIII, 135: canit; 152: cano; 183: canit y 188: canit. Stoehr-Monjou, "L'apparition d'Apollon dans le Rapt d'Hélène", 142, n. 11 considera que el verbo cano, utilizado por Apolo para aludir a la intervención profética de Casandra, conlleva un valor peyorativo. No obstante, la forma seleccionada parece inscribirse en la tradición épica cristiana inaugurada por Juvenco, consistente en asignar el verbo cano sólo a la acción de los profetas, cf. Iuv. I, 116; 122; 141; 313; II, 104; y 4, 637. Sobre el tema, cf. Marrón, G., "Análisis del proemio del De raptu Helenae de Draconcio. Inserción genérica y programa poético", en: Florio, R., Varia et diversa, Santa Fe, Ediciones UNL, 2018 [en prensa]. 
la configuración del mismo personaje en la Eneida ${ }^{12}$. Si bien, en ambos casos, la alusión al texto de Estacio plantea cierta resignación ante la imposibilidad de cambiar el curso de los acontecimientos profetizados, Casandra comparte con Anfiarao un destino personal de carácter trágico; Heleno, en cambio, sobrevivirá al fuego y a Pirro, para reinar en Épiro como esposo de Andrómaca. No obstante, hay otro elemento común a los tres adivinos ${ }^{13}$, articulado en el texto de Draconcio inmediatamente después de la intervención de Casandra, cuando se le asigna a Apolo un epíteto toponímico poco frecuente la literatura latina -Thymbraeus Apollo (Drac. Romul. VIII, 184) ${ }^{14}-$, que no sólo establece un nuevo vínculo con el ya citado discurso de Anfiarao ${ }^{15}$, sino que, como veremos más adelante, también sitúa su inminente aparición bajo la óptica de la épica postvirgiliana $^{16}$.

12 Cf. Drac. Romul. VIII, 120: exclamat; 134: loquitur; 189: exclamat. En el texto virgiliano, Heleno domina diversos ritos adivinatorios, cf. Verg. Aen. III, 350-361; y Cairo, M. E., "Signos y profecías en el libro III de Eneida", Auster 14, 2009, 63-83, 77: "en primer lugar, aparecen los atributos de los oráculos griegos de Apolo (los trípodes, los laureles), con la mención específica de Claro; en segundo lugar, se menciona la astrología, asociada a Oriente; finalmente, el arte augural romano que descifra el canto y el vuelo de los pájaros. Heleno, pues es una especie de adivino 'total', conocedor de múltiples modos de contacto con la divinidad. Es a la vez uates $(358,463)$, interpres (359) y sacerdos (373)."

13 Cf. Bouquet, J. y Wolff, É., Dracontius. Oeuvres. Tome III, Paris, Les Belles Lettres, 2002, 65: "Dracontius n'imite jamais Stace au hasard, c'est, selon un principe déjà mis en lumière, una similitude ou une analogie de situations qui provoque la réminiscence."

14 Como epíteto de Apolo, Thymbraeus aparece sólo diez veces en composiciones poéticas (dos en Virgilio, siete en Estacio y una en Draconcio): Verg. G. IV, 323; Aen. III, 85; Stat. Theb. I, 643; 699; III, 513; 638; IV, 515; Silv. I, 4, 117; IV, 7, 22; y Drac. Romul. VIII, 184. A su vez, referencias a Thymbra, explícitamente en relación con dicha divinidad, hay sólo cuatro (tres en Estacio y una en Sidonio): Stat. Theb. VIII, 202; Silv. I, 2, 222; III, 2, 97; y Sidon. carm. 9, 176. El sintagma Thymbraeus Apollo completo aparece sólo en Verg. G. IV, 323, donde ocupa la misma posición métrica que en el texto de Draconcio. Nos ocuparemos más adelante tanto de esta, como de la otra referencia virgiliana enunciada aquí. Acerca de la simbología del nombre propio Thymbraeus, atribuido a un guerrero troyano que se enfrenta con otro llamado Osiris en la Eneida, cf. Reed, J. D. "The Death of Osiris in Aeneid 12.458", AJPh, 119, 1998, 399-418.

15 Cf. Stat. Theb. III, 637-640: consulti testor penetralia mundi / et uolucrum adfatus et te, Thymbraee, uocanti / non alias tam saeue mihi, quae signa futuri / pertulerim.

16 En la Tebaida, la primera mención de Apolo en relación con Timbra ocurre dentro del relato etiológico referido por Adrasto a Tideo y Polinices, cuando Corebo se dirige a la divinidad utilizando ese epíteto (cf. Stat. Theb. I, 643: Thymbraee). Acerca de la inversión que supone dicho episodio con relación al modelo eneádico, donde Evandro narra a Eneas el enfrentamiento de Hércules y Caco, cf., por ejemplo, McNelis, C., Statius Thebaid and the Poetics of Civil War, Cambridge: Cambridge University Press, 2007, 27-29. Con respecto a las diferencias entre el Apolo virgiliano y el de Estacio, cf., por ejemplo, Ganibal, R. T., Statius and Virgil. The Thebaid and the Reinterpretation of the Aeneid, Cambridge, Cambridge University Press, 2007, 21: "Apollo can be proudly worshiped by the Argives, for he has the demonstrated ability to exercise clementia. That he is a cruel deity, seemingly blind to the suffering of the Argives, is from their perspective not particularly important. In this world of oppressive autocracy, clementia offers the only hope to the ruled against the immense powers of rulers. Clementia, not pietas, has become the ideal virtue in the Thebaid's world of tyrants." 
Tanto Tzetzes, como los escoliastas de Homero narran que Heleno y Casandra adquirieron el don de la profecía cuando aún eran niños de pecho, debido a que dos serpientes les lamieron las orejas mientras se hallaban en el templo consagrado a Apolo en Timbra ${ }^{17}$. Según testimonia Servio, a su vez, Euforión de Cálcides refería que Laoconte, tras haber sido primero pontífice de Apolo Timbreo, fue luego sorteado para sustituir al anterior sacerdote de Poseidón, que había sido lapidado por los troyanos al no lograr destruir la flota griega ${ }^{18}$. La relación de Laoconte con el templo de Apolo en el monte Timbro resulta significativa, ya que otras tradiciones relacionaban con dicha divinidad las dos serpientes que, según leemos en la Eneida, emergen del mar para matarlo junto a su hijo; portento interpretado como un castigo de Atenea por haber arrojado su lanza contra el caballo de madera supuestamente consagrado a ella por los griegos ${ }^{19}$. En el texto de Draconcio, justo antes de ser interrumpida por la aparición de Apolo, Casandra finaliza su discurso señalando que tanto Heleno, como Laoconte poseían la autoridad religiosa necesaria para llevar a cabo el sacrificio ritual de Paris ${ }^{20}$. A su vez, el final del verso anterior a la aparición de Apolo Timbreo en El Rapto de Helena, remite al pasaje de la Eneida en que, ya muerto Laoconte y pese a las advertencias de la sacerdotisa, los troyanos ingresan el caballo de madera en la ciudad:

et monstrum infelix sacrata sistimus arce. tunc etiam fatis aperit Cassandra futuris ora dei iussu non umquam credita Teucris.

(Verg. Aen. II, 245-247) ...e ingresamos el desdichado monstruo en nuestra fortaleza sagrada. También entonces Casandra -a quien los teucros, debido al mandato divino, nunca le creyeron- abrió su boca y reveló los futuros hados.

Dum canit infelix gemitus Cassandra futuros

(Drac. Romul. VIII, 183)

17 Cf. schol. Hom. Il. VI, 76a; VII, 44-45; Tzetz. Lycophr. Alex. genus. 26-42; y Ogden, D., Drakon: Dragon Myth and Serpent Cult in the Greek and Roman Worlds, Oxford, Oxford University Press, 2013, 138.

18 Cf. Serv. Verg. Aen. II, 201.

19 Cf. Verg. Aen. II, 40-56, 199-233; y Ogden, Drakon: Dragon Myth and Serpent Cult, 135-138.

20 Cf. Drac. Romul. VIII, 178-182: Si forte profanus / hunc feriet quicunque reum, sit in urbe sacerdos: / cedo; loco si forte meo pius esse recusat, / pontifices Helenus Laocon, sacrata potestas, / cedent oranti uel mysticus extat uterque ("Si cualquier persona no iniciada accede a matar al culpable, que la ciudad la designe sacerdote para hacerlo: cedo mi puesto. Si nadie acepta cumplir esa obligación en mi lugar, las autoridades religiosas, Heleno y Laooconte, facultados para llevar a cabo sacrificios, accederán a mis ruegos y lo ejecutarán juntos"). A su vez, como señala Stoeh-Monjou, "L'apparition d'Apollon dans le Rapt d'Hélène", 153: "Le traitre Sinon invente une fausse prophétie d'Apollon exigeant le sacrifice d'un Grec, alors que le discours d'Apollon va sauver Pâris de l'immolation voulue par Cassandre." 
Mientras la desdichada Casandra profetiza los futuros lamentos...

El paralelismo establecido por Draconcio entre las dos situaciones es claro $^{21}$ : en ninguno de ambos contextos pueden los teucros comprender -o creer- las palabras de Casandra; sin embargo, si recibir a Paris en Troya supone desencadenar la destrucción de Pérgamo, cuando el caballo de madera atraviese las murallas, ya se encontrará fatídicamente adentro. La maestría del poeta africano consiste, entonces, en construir un encadenamiento causal que, si bien sigue el hilo narrativo de la fábula, en realidad invierte la secuencia compositiva de los textos. El ingreso de Paris en Troya es ya el del caballo de madera, pero son los sintagmas virgilianos los que permiten construir e investir de significado la correlación propuesta. Del mismo modo, sólo un lector de la Eneida puede entender el sentido subyacente tras la ambigüedad de la profecía articulada por Apolo ante los troyanos y saber que ese imperio sin fin prometido no es el de los teucros, sino el anunciado por Júpiter para los romanos en el poema de Virgilio. En el siguiente apartado, intentaremos demostrar que el entramado intertextual elaborado por Draconcio se orienta, sin embargo, a la comprensión de lectores cristianos $^{22}$, para quienes Apolo, como todo dios pagano, siempre representa creencias falsas y, por lo tanto, también es portador de un discurso falaz en la Eneida. Algunos pasajes de las obras escritas durante el siglo anterior por Agustín de Hipona en el norte de África nos permitirán contextualizar la línea interpretativa propuesta.

Tanto en El rapto de Helena, como en la Tebaida, la mención de Timbra en relación con Apolo evoca la construcción de las murallas troyanas, pero Draconcio

21 Cf. Simons, Dracontius und der Mythos, 245; y Stoeh-Monjou, "L'apparition d'Apollon dans le Rapt d'Hélène", 152-153.

22 Cf. Bright, D., The Miniature Epic in Vandal Africa, Norman, University of Oklahoma Press, 1987, 100: "The contrast between Cassandra, who speaks the truth but is not believed, and the god of prophecy who misleads but is believed, is quite possibly due to more than the demands of plot. We have seen in Medea how the poet appears to discredit the worship of the gods, and in Hylas how they may even be objects of ridicule. This deception by the god of truth may be another example of the Christian poet's view of the old gods"; y Wasyl, Genres rediscovered, 58: "By portraying with all his rhetorical skill of an excellent lawyer Apollo the sophist, he warns against not merely a false pagan divinity but, above all, against the danger and the power of a word." 
señala, de manera explícita, que el motivo subyacente tras el engañoso vaticinio del dios es castigar a los frigios por la ingratitud de su ancestro, Laomedonte ${ }^{23}$ :

seu Troiam Thymbraeus habes, ubi fama uolentem ingratis Phrygios umeris subiisse molares, (Stat. Theb. I, 699-700)

o bien residas en Troya, bajo el nombre de Timbreo, donde la fama refiere que soportaste voluntariamente las piedras frigias sobre tus hombros no recompensados.

Dum canit infelix gemitus Cassandra futuros, uisus adest cunctis Phrygibus Thymbraeus Apollo, qui mercede carens conclusit Pergama muro et genus ingratum poenas persoluat auari exoptat: stupuere Phryges, tacet ipsa ${ }^{24}$ sacerdos. (Drac. Romul. VIII, 183-187)

Mientras la desdichada Casandra profetiza los futuros lamentos, se presenta ante todos los frigios Apolo Timbreo, quien rodeó Pérgamo con un muro sin recibir retribución y desea que la desagradecida estirpe del avaro pague por ese delito: quedan atónitos los frigios, la propia sacerdotisa se calla.

Según indica la voz narrativa, el dios desea que esa ingrata estirpe (genus ingratum, Drac. Romul. VIII, 186) expíe la falta heredada de su avaro ancestro y, por esa razón, pronuncia ante los teucros una profecía que explota tendenciosamente la característica amphibolía ${ }^{25}$ de sus vaticinios. La secuencia conformada por las intervenciones de Heleno, de Casandra y de Apolo culmina con una predicción de argumento histórico, que parece aludir a la futura gloria de Roma: fata manent, conscripta semel sunt uerba Tonantis, / imperium sine fine dabit ${ }^{26}$. Sin embargo, no debemos perder de vista que, cuando Draconcio escribe, Apolo ya no se encuentra en la Roma de Virgilio, sino en África, un territorio literario donde su figura había sido ya recibida e interpelada un siglo antes por Agustín de Hipona:

$23 \mathrm{Cf}$. Wasyl, Genres rediscovered, 81: "A careful reader must know from the very beginning that whatever Apollo will do shall be done to take revenge of the Trojans. Consequently, he/she should not be much surprised finding out that the god turns out a sophist, manipulating the truth and misleading his human audience." De Gaetano, Scuola e Potere in Draconzio, recupera la relación ya establecida por Vollmer entre los sintagmas et genus inuisum (Verg. Aen. I, 18) y et genus ingratum (Drac. Romul. VIII, 186) y señala: "Equiparando Apollo a Giunone, nemica tradizionale della stirpe troiana, Draconzio sembra voler contraddire l'affidabilità della funzione tutelare del dio pagano e svelarne quella segretamente ostile." Stoehr-Monjou, "L'apparition d'Apollon dans le Rapt d'Hélène", 149, considera que el epíteto inuisum, asignado por Apolo a Heleno, constituye también un eco del sintagma virgiliano genus inuisum.

24 Verso 187: ipsa Iannelli Duhn Bährens Grillone 2006: ipse N Vollmer Díaz de Bustamante Wolff. 25 Cf. Guerrieri, "Scene di profezia nel De raptu Helenae", §16.

26 Drac. Romul. 8, 198-199: "Los hados persisten, ya fueron escritas una vez las palabras del Tonante: les concederá un imperio sin fin". 
Primum ipsa Troia uel Ilium, unde origo est populi Romani, (...) eosdem habens deos et colens quur a Graecis uictum, captum adque deletum est? "Priamo, inquiunt, sunt reddita Laomedontea paterna periuria". Ergo uerum est, quod Apollo adque Neptunus eidem Laomedonti mercennariis operibus seruierunt? Illis quippe promisisse mercedem falsumque iurasse perhibetur. Miror Apollinem nominatum diuinatorem in tanto opificio laborasse nescientem quod Laomedon fuerat promissa negaturus. Quamquam nec ipsum Neptunum, patruum eius, fratrem Iouis, regem maris, decuit ignarum esse futurorum. Nam hunc Homerus de stirpe Aeneae, a cuius posteris [condita] Roma est, cum ante illam urbem conditam idem poeta fuisse dicatur, inducit magnum aliquid diuinantem, quem etiam nube rapuit, ut dicit, ne ab Achille occideretur, cuperet cum uertere ab imo, quod aput Vergilium confitetur, structa suis manibus periurae moenia Troiae. Nescientes igitur tanti di, Neptunus et Apollo, Laomedontem sibi negaturum esse mercedem, structores moenium Troianorum gratis et ingratis fuerunt. Videant ne grauius sit tales deos credere quam di talibus peierare. Hoc enim nec ipse Homerus facile credidit, qui Neptunum quidem contra Troianos, Apollinem autem pro Troianis pugnantem facit, cum illo periurio ambos fabula narret offensos. Si igitur fabulis credunt, erubescant talia colere numina; si fabulis non credunt, non obtendant Troiana periuria, aut mirentur deos periuria punisse Troiana, amasse Romana. (August. De civ. D., III, 2) ${ }^{27}$

En primer lugar, ¿por qué Troya -o Ilión-, cuna del pueblo romano (...), adorando ambos pueblos los mismos dioses, por qué Troya fue vencida, tomada y arrasada por los griegos? "Príamo -se dice- tuvo que pagar los perjurios de su padre, Laomedonte." Luego, ¿es verdad que Apolo y Neptuno trabajaron a sueldo para Laomedonte? Porque, al parecer, éste les prometió un sueldo y juró en falso. Me sorprende que un Apolo, llamado el Adivino, trabajase tan penosamente, sin saber que Laomedonte no iba a cumplir su promesa. Aunque en realidad tampoco le cae bien desconocer el futuro al mismo Neptuno, su tío, rey del mar, hermano de Júpiter. Porque Homero, poeta, según tradición, anterior a la fundación de Roma, presenta a este dios haciendo una profecía importante sobre la raza de Eneas, cuyos descendientes fundaron Roma. Asimismo nos presenta a Neptuno arrebatándolo en una nube para librarlo de morir a manos de Aquiles. Y Virgilio confirma también: "Estaba deseando arruinar de raíz aquellos muros de la perjura Troya, construidos por sus propias manos". Así que unos dioses tan importantes como Neptuno y Apolo, al ignorar que Laomedonte les iba a negar la paga, se convirtieron en constructores, actuando gratis y para ingratos, de las murallas de Troya. Miren a ver los paganos si no es más grave creer a tales dioses que hacerles perjurio. El mismo Homero no se lo creyó fácilmente, puesto que nos presenta a Neptuno luchando contra los troyanos, y a Apolo a favor de ellos, siendo así que según la leyenda ambos están ofendidos por el mismo perjurio. En fin, si tienen fe en las leyendas, sientan rubor de dar culto a tales divinidades, y si no la tienen, que no pongan como pretexto los perjurios de Troya; o, también, que se admiren de que los dioses han castigado los perjurios de Troya, y han sentido simpatía por los de Roma. ${ }^{28}$

La misma operación realizada por el autor de El rapto de Helena al colocar dentro

del discurso de Apolo una cita de la profecía de Júpiter a Venus en la Eneida (imperium

27 Citamos los textos cristianos por las ediciones incluidas en Library of Christian Latin Texts, CLCLT-2 CD ROM, Universitas Catholica Lovaniensis, Turnhout, Brepols, 1994.

28 Traducción tomada de Santamaría del Río, S., Fuentes Lanero, M. y Capanaga, V., Agustín de Hipona. La Ciudad de Dios, Madrid: Biblioteca de Autores Cristianos, 1972. 
sine fine dedi, Verg. Aen. I, 272) se observa en el citado fragmento de La ciudad de Dios, donde Agustín había reescrito -también en tercera persona- otras palabras dirigidas por Neptuno a la madre de Eneas en el poema de Virgilio:

cuperem cum uertere ab imo structa meis manibus periurae moenia Troiae. (Verg. Aen. V, 810-811)

Cuando [yo] deseaba arrancar de raíz las murallas de la perjura Troya, construidas por mis propias manos.

cuperet cum uertere ab imo

structa suis manibus periurae moenia Troiae. (August. De civ. D., III, 2)

Cuando [él] deseaba arrancar de raíz las murallas de la perjura Troya, construidas por sus propias manos.

Entre los distintos argumentos desarrollados por Agustín, el más relevante para comprender el vaticinio de Apolo en El rapto de Helena consiste en equiparar el perjurio con la adoración de los dioses paganos. En tanto divinidad profética, Apolo no podía ignorar que Laomedonte juraba en falso y no pagaría lo convenido por la construcción de la muralla, pero la realizó igual y luego se vengó de sus descendientes, al señalar a Paris como el único capaz de derrotar a Aquiles y anunciarles un imperio sin fin, pese a que Príamo - como indica la voz narrativa del texto de Draconcio- se le someta y rinda culto con devoción (Phoebum Priamus summissus adorat, Drac. Romul. VIII, 211 ${ }^{29}$. Con respecto a la profecía de la muerte de Aquiles a manos de Paris, resultan significativos dos aspectos: por un lado, la alusión a las diversas variantes míticas que se refieren la emboscada sufrida por el Pélida, precisamente, en el templo de

29 Cf. Stat. Theb. VIII, 284: oblatas frondes summisus adorat (acerca de Teodamás, cuando sustituye a Anfiarao como intérprete de Apolo en el ejército de Adrasto). Los autores cristianos retoman el sintagma para referirse a la adoración de Cristo, cf. Juvenc. Evang. III, 500: Christumque palam summissus adorat; Prosp. Prou. 768: solum Vnigenam summissus adorat; o de las sagradas escrituras, cf. Prud. Apoth. 598: dum rutilos apices summisus adoro. En Sidon. carm. II, 388, en cambio, la expresión se aplica a la adoración de Roma como divinidad (el río Tíber se postra ante ella); y en Claud. Hon. III, 122, a la del emperador. En este caso, es probable que el sintagma refiera a la Tebaida sólo a través de la reelaboración de Juvenco, retomada por Prudencio y por Próspero de Aquitania, para marcar el constraste entre el culto a los dioses paganos y al Dios cristiano. Muchos de los modelos clásicos son sólo disparadores iniciales en la cadena de alusiones, como arquetipo que dan lugar al establecimiento de vínculos, incluso más significativos, entre la obra de un determinado autor cristiano y la de otros autores cristianos precedentes. $\mathrm{Al}$ respecto, cf., por ejemplo, la interpretación del verso imperii per saecla tui sine fine manentis (Drac. Laud. II, 24) y su relación con el sintagma imperium sine fine manet (Sedul. Pasch. II, 55), a través del arquetipo imperium sine fine dedi (Verg. Aen. I, 270), en Stella, F., "Epic of the Biblical God: Intercultural Imitation and the Poetics of Alterity", en Paschalis, M. (ed.) Roman and Greek Imperial Epic, Crete, Herakleion, 2005, 131-145, 136. 
Apolo Timbreo ${ }^{30}$; por otro, la nueva relación intertextual que se establece entre este pasaje y la obra de Estacio:

magnanimum Aeacidem solus prosternet Achillem (Drac. Romul. VIII, 192)

Al magnánimo Eácida, Aquiles, sólo él lo derrotará.

$\underline{\text { magnanimum }} \underline{\text { Aeaciden }^{31}}$ formidatamque Tonanti

progeniem et patrio uetitam succedere caelo,

diua, refer. (Stat. Ach. I, 1-3)

Al magnánimo Eácida, descendiente temido por el Tonante y al que se le impidió heredar el cielo paterno, refiérete, diosa.

El Apolo del poema de Draconcio habla antes de que se produzca la guerra de Troya, pero parece haber leído ya no sólo la Eneida, sino también la Aquileida, obra en cuyo proemio Estacio le pediría inspiración precisamente a él: da fontes mihi, Phoebe (Stat. Ach. I, 9). Si el poeta sugiere, entonces, que la venganza personal de Apolo supone tanto la ruina de los troyanos, como la de Aquiles, ¿qué papel pueden desempeñar las divinidades paganas en el futuro de Roma? Si el imperio sin fin anunciado por Apolo a los frigios habla en realidad del correspondiente a los romanos, ¿qué certezas puede brindar a los lectores de Virgilio la profecía revelada por Júpiter en la Eneida? Si la desaparición de Troya era condición para la fundación de Roma, ¿cómo interpretar el saqueo de Alarico? Recordemos que, en Delos, al elevar su plegaria a Apolo y solicitar una ciudad eterna, Eneas también se dirige al dios como Thymbraeus:

"da propriam, Thymbraee, domum; da moenia fessis
et genus et mansuram urbem; serua altera Troiae
Pergama, reliquias Danaum atque immitis Achilli."

Danos, Timbreo, una morada propia; danos murallas para nuestra fatiga, y también descendencia y una ciudad que dure para siempre; protege a la nueva ciudadela de Troya

30 Sobre las distintas fuentes y variantes en torno a la muerte de Aquiles en el templo de Apolo Timbreo, cf., por ejemplo, la síntesis ofrecida en Bretzigheimer, G., op. cit, 383, n. 69 y 70. Es importante recordar, a su vez, que algunas variantes míticas señalan el templo de Apolo en Timbra como el sitio donde Aquiles mata a Troilo, personaje a cuya muerte aluden tanto la profecía de Casandra, como la de Heleno en el poema de Draconcio, cf. Apollod. Epit. III, 32; y el comentario de Thomas, R. F., Virgil. Georgics: vol. 2, Books III-IV, Cambridge, Cambridge University Press, 1988, 205: "The words si pater est Thymbraeus Apollo belong as a taunt in the mouth of Achilles as he is about to kill Troilus (suggesting that the latter get help from his 'father'), and it is quite possible that Virgil has adapted them (whether Greek or Latin cannot be known) to a new situation."

31 Cf. Stoehr-Monjou, "L'apparition d'Apollon dans le Rapt d'Hélène", 150: "De fait, l'alliance magnanimum Aeacidem est empruntée aux premiers mots de l'Achilleide, réécriture de magnanimum Aenean (également en attaque de vers) dans la prophétie de Jupiter à Venus" (Verg. Aen. 1, 260). 
y a estos restos que han dejado los dánaos y el implacable Aquiles.

La alusión a la promesa de Júpiter en la Eneida se encuentra presente en varias obras que median entre Virgilio y Draconcio ${ }^{32}$. Agustín de Hipona, por ejemplo, retoma el sintagma imperium sine fine dedi, polemizando con él -y acaso también con el citado pedido de Eneas-, en el Sermón 105, cuando imagina la hipotética respuesta de Virgilio ante un eventual pedido de explicaciones por la falsedad de esa frase:

Forte si uellemus hinc exagitare Virgilium, et insultare, quare hoc dixerit; in parte tolleret nos, et diceret nobis: "Et ego scio; sed quid facerem qui Romanis uerba uendebam, nisi hac adulatione aliquid promitterem quod falsum erat? Et tamen et in hoc cautus fui, quando dixi, Imperium sine fine dedi, Iouem ipsorum induxi, qui hoc diceret. Non ex persona mea dixi rem falsam, sed Ioui imposui falsitatis personam: sicut Deus falsus erat, ita mendax uates erat. Nam uultis nosse quia ista noueram? Alio loco, quando non Iouem lapidem induxi loquentem, sed ex persona mea locutus sum, dixi: Non res Romanae perituraque regna. Videte quia dixi peritura regna. Dixi peritura regna, non tacui. Peritura, ueritate non tacuit: semper mansura, adulatione promisit." (August. Serm. 105, 10)

Si quisiéramos llamar a cuentas a Virgilio y reprocharle el haber dicho tales cosas, quizá nos llevara a un rincón para decirnos: "También yo lo sé, pero para vender mis palabras a los romanos, ¿qué iba a hacer sino prometerles adulatoriamente lo que era falso? Ten en cuenta que al decir 'les di un imperio eterno' obré con cautela, pues lo puse en boca de Júpiter. Personalmente no dije falsedad alguna; el papel de mentiroso lo dejé para Júpiter. ¿Queréis comprobar que ya sabía yo eso? En otro lugar en que hablaba en nombre propio, sin introducir ya al Júpiter de piedra, dije: 'ni los propios asuntos de Roma, ni los reinos mismos destinados a perecer'. Ved que dije que 'los reinos han de perecer'. Lo dije; no callé que 'los reinos han de perecer.' 'Han de perecer': hablando en verdad no lo callé; 'han de pervivir siempre': es promesa que nace de la adulación." 33

Si bien no existe consenso acerca de cómo leer la inclusión del mencionado sintagma virgiliano en el discurso de Apolo, algunos críticos remiten a ese fragmento de los Sermones de Agustín y sostienen que la idea de un "imperio sin fin" era considerada ya completamente falsa por los cristianos del siglo $\mathrm{V}$, incluso con relación al futuro de la Roma conversa ${ }^{34}$. Una posible forma de comprender la frase es proyectarla a un orden

32 Cf., por ejemplo, Sulp. Sat. 34; Tert. Apol. 25, 16; Proba, Cento 143; Prud. Symm. I, 542: imperium sine fine docet; y Sedul. carm. Pasch. II, 55: imperium sine fine manet.

33 Traducción tomada de Cilleruelo, L., Campelo M., Morán, C. y De Luis, P., Obras Completas de San Agustín, tomo X, Madrid: Biblioteca de Autores Cristianos, 1986.

34 Cf., por ejemplo, De Gaetano, Scuola e Potere in Draconzio, 171: "c'è chi vede in questo brano una dichiarazione di fede da parte di Draconzio nella provvidenzialità del fati e nell'imperiura elezione di Roma al dominio mondiale. In realtà, non si tiene conto che il poeta compie uno slittamento contestuale che cambia di segno il testo virgiliano. (...) L'intenzione della divinità in Draconzio è puramente dolosa: rassicurare per distruggere"; y Simons, Dracontius und der Mythos, 290: "Wenn Apollo die Prophezeiung 
trascendente, que exceda la dimensión terrenal de cualquier reino presente o futuro; esa es, precisamente, la idea sintetizada por Agustín de Hipona en La Ciudad de Dios, cuando recurre redefine el Imperio desde una perspectiva celeste y eterna ${ }^{35}$ :

Nunc iam caelestem arripe, pro qua minimum laborabis, et in ea ueraciter semperque regnabis. Illic enim tibi non Vestalis focus, non lapis Capitolinus, sed Deus unus et uerus nec metas rerum nec tempora ponit, / imperium sine fine dabit. (August. De civ. D., II, 29)

Ahora apodérate de la patria celestial. Te va a costar poco conseguirla, y en ella caminarás de verdad y por siempre. Allí no tendrás el fuego de Vesta ni la piedra del Capitolio, sino al único y verdadero Dios, que "no pondrá mojones ni plazos a tus dominios; te dará un imperio sin fin".

Draconcio que es un autor cristiano, escribe El rapto de Helena en el norte de África, durante el siglo inmediatamente posterior a la aparición de La ciudad de Dios. Propone allí el encadenamiento de las tres profecías que hemos analizado y a las que se impone volver a mirar prestando particular atención a la dimensión enunciativa. No es el autor del poema, ni la representación narrativa de su persona quien cita la profecía virgiliana acerca del futuro eterno del imperio romano, sino Apolo, un personaje que, como el Júpiter virgiliano, puede redefinirse en los términos propuestos por Agustín de Hipona: sicut Deus falsus erat, ita mendax uates erat. Las profecías de Casandra y de Heleno no se proyectan sobre la dimensión histórica externa a la narración mítica y, como Anfiarao en la Tebaida, nada pueden hacer para cambiar lo que ya ha sido escrito (en este caso, no por el fatum, sino por los autores de la tradición literaria precedente). Apolo, en cambio, al ser la única divinidad que interviene en la trama, cumple una función estructural distinta, permitiéndole al autor entablar un diálogo polémico con el universo del panteón pagano, pero ya no en el orden expositivo característico de un tratado teológico o filosófico -como lo había hecho Agustín de Hipona- sino en el marco de una narración poética que reconfigura la trama mitológica a partir de la nueva ideología cristiana.

Jupiters über das imperium sine fine wiederholt, ist dies nicht nur ein Betrug gegenüber den Trojanern, weil das Römische Reich den Untergang Trojas voraussetzt, sondern Ende des 5. nachchristlichen Jahrhunderts hat sich diese Prophezeiung auch für das Römische Reich als falsch erwiesen.” 35 Cf. Schildgen, B., Divine Providence: A History: The Bible, Virgil, Orosius, Augustine, and Dante, London / New York, University of California Press, 2012, 74.

Traducción tomada de Santamaría del Río, Fuentes Lanero, y Capanaga, Agustín de Hipona. La Ciudad de Dios. 
La tradicional ambigüedad del discurso profético de cualquier divinidad o vate pagano se presta, particularmente, para la articulación de los diversos niveles de sentido propuestos por Draconcio. En el caso aquí analizado, ello produce como resultado un entramado textual donde la citación de otros autores no sólo supone asignar un nuevo significado a los mismos sintagmas dentro de El rapto de Helena, sino también invitar al lector a repensar el sentido de los pasajes citados $-\mathrm{y}$ la función desempeñada por sus enunciadores- en sus contextos de inserción originales. Apolo, lector de Estacio y de Virgilio, los reescribe al retomar fragmentos de sus obras; no sólo para engañar a los troyanos, sino también para recordarle a los lectores que la Aquileida, la Eneida y sus respectivos héroes serán conducidos al mismo desenlace trágico que su ambigua profecía le ha ocultado a los teucros ${ }^{36}$. Consecuentemente, tanto la leyenda de Troya, como la memoria de la fundación de Roma parecen orientarse, en El rapto de Helena, hacia la misma función instrumental: recordar que su desaparición era necesaria para el advenimiento de un credo de orden superior, el cristiano.

Gabriela Andrea Marrón Universidad Nacional del Sur - CONICET marron.gabriela@gmail.com

\section{Resumen:}

En el apartado inicial de este trabajo a analizaremos la disputa entablada por Draconcio a partir de la apropiación y reinserción de ciertos sintagmas de Virgilio y de Estacio, orientados a establecer la naturaleza falaz y engañosa de la profecía de Apolo en El rapto de Helena. En la segunda parte, mostraremos que la caracterización despectiva de dicha divinidad en el poema se proyecta, a su vez, hacia el universo textual de la Eneida, proponiendo una lectura inscripta en la misma línea exegética desarrollada en África, un siglo antes, por Agustín de Hipona.

Palabras clave: Febo Apolo - profecía - Virgilio - Estacio - Draconcio

Abstract:

36 Acerca de la importancia de la exégesis de las profecías virgilianas y del Antiguo Testamento en la obra de Draconcio, cf. Marrón, G. A., "Furor impius / non impira ira: Comparaciones de hombres con leones en la obra de Blosio Emilio Draconcio", Euphrosyne 45, 2017, 79-95. Sobre la ambigüedad como clave interpretativa planteada en el proemio de El rapto de Helena, cf. Marrón, “Análisis del proemio del De raptu Helenae". 
In the first part of this article we will analyze the discussion established by Dracontius through the appropriation and reinsertion of certain Virgilian an Statian syntagmas, orientated to show the fallacious and treacherous nature of Apollo's prophecy in the De raptu Helenae. In the second part, we will demonstrate that the negative characterization of this divinity in the poem is projected, in turn, towards the textual universe of the Aeneid, proposing a reading inscribed in the same exegetical line developed in Africa, a century before, by Augustine of Hippo.

Keywords: Phoebus Apollo - prophecy - Virgil - Statius - Dracontius

RECIBIDO: 1-8-2017 - ACEPTADO: 4-11-2017 